This is an open access article under the CC BY-NC-ND license (https://creativecommons.org/licenses/by-nc-nd/3.0/) Issue III, November 2020

ISSN 2707-9481

ISBN 978-601-323-207-2

https://doi.org/10.31643/2020.018

\author{
Inga Milevica \\ Alberta College, Latvia \\ E-mail: inga.milevica@gmail.com \\ ORCID ID 0000-0002-4948-8655
}

\title{
Rhetorics and challenges of distant education
}

\begin{abstract}
Distant education has become a stable form implementing higher education. Advantages and disadvantages of this distant education form have been discussed since the form was introduced. Interactivity with a strong visual component, effective communication in various combinations - one on one, duet, group - and active learning with informative, moral, institutional support from the very beginning have been declared as one of the greatest benefits distant education. But today we are already talking about interactivity's deficiencies, how we return to the problem of routine one-way education. There is a reason why there are regular studies in distant education research on contact forms becoming more favorable than distant forms, as they are chosen by students more frequently. The time, we enjoy in digital opportunity studies, already shown a number of stereotypes about e-studies, among which, the college highlights the following: e-studies resembled boring self-learning process with static study materials and monotonous video recordings due to lack of usual lecture form, where the lecturer meets with the group, help them with study materials; there was a lack of lectures where you can meet fellow students, exchange views and work in groups.
\end{abstract}

Keywords: Distant Education, COVID-19, Rhetorics, Approaches, Stereotype.

\section{Introduction}

Distant education has become a stable, require and almost mandatory form implementing higher education: teachers post tasks, tests, requirements, literature lists etc. online, reading lectures, consult, test and accept exams for part-time e-study or part-time with e-study elements students who have many objective arguments and reasons in both inside the education system itself and outside of it.

In the COVID-19 situation, the advantages and disadvantages of distance learning became clearer than ever, and a critical assessment of this experience is yet to come, although already during the pandemic, representatives of the education sector at different levels have started to actively share their experiences and conduct research. Undeniably, one of the most important COVID lessons in education: both sides of the learning process, "teachers and students, especially educational institutions, should be prepared for these environments. It has been argued that distance learning policy for facing pandemic COVID-19 should be modified because not all schools are ready to teach online and provide online lessons" (Arlinwibowo et al., 2020). Trainings can be carried out so that teachers and students can adapt to distance education more easily, and the necessary infrastructure support can be further strengthened to eliminate technical problems". (Hebebci, Bertiz, Alan, 2020, P. 279). In one of the most diligent studies examined and compared the training tactics of universities in 20 countries during the pandemic, emphasizing that "higher education may be a valuable addition to their productive home environments in the short and potentially medium-term". (Crawford, Butler-Henderson, Rudolph, Malkawi, Glowatz, Burton, Magni, Lam, 2020, p. 20). Thereby “need a high level of preparedness so that we can quickly adapt to the changes in the environment and can adjust ourselves to different delivery modes, for instance, remote learning or online learning in situations of pandemics such as Covid-19” (Dhawan, 2020, p. 18). 
Distant form of learning cannot be referred to as new: as early as the 1990s, this form was subject to regular attention from researchers and practitioners. In the mid-90s, Lorraine Sherry said something what still sounds relevant today: "Today, political and public interest in distance education is especially high in areas where the student population is widely distributed" (Sherry, 1995, P. 340). Of course, the use of distant forms differs in different countries, in different education institutions, through experience of different teachers. All of us, supposedly and hopefully, have an understanding of the role of this form. We all understand that the distant form of education is an important element in the image of our educational institutions, and also in professional image of teacher.

The origins of distance learning come from Europe. According to Lorraine Sherry, who has made a historical insight into the distance learning field, the origins of distance learning can be found in study forms of European correspondence: The earliest form of distance learning took place through correspondence courses in Europe. This was the accepted norm until the middle of this century, when instructional radio and television became popular” (Sherry, 1995, P. 339).

Putting forms of distance learning alongside such popular forms as radio and more - television especially in the early stages, contributed to the positive image of distance learning, which in the naive world scene has a semantics of entertainment and ease. At a later stage, this semantics remains, however the semantics of monotony and boredom appear. Such semantics with different axiology also have been addressed with great attention from researchers.

\section{Literature review}

Advantages and disadvantages of this distant education form have been discussed since the form was introduced. Many articles have been dedicated to issues of distant education dealing with a number of metaanalyzes, and it would take lots of pages to even create a list of them: theoretical studies evolve in one hand with practical experience year after year. Technological innovations and skills of institutions and teachers also play their role in developing constant curiosity.

Over the years the target audience of distance learning is widening and naturally specializing and segmenting. "Traditionally, we think of distance learners as adults" (Sherry, 1995, P. 342). If such a statement was topical in the 1990s, now we almost do not see the boundaries of age spectrum, nor do we see the boundaries of distance learning's forms, platforms and opportunities. This situation contributes to conducting research devoted to the discovery of differences between different ages, social groups, professional groups, people with special needs, including gender-oriented groups in distance learning discourses. One of results of these studies in many countries has resulted in an institutional formation such as inclusive education departments in universities.

With time, the range of concepts that make up a separate terminological problem has naturally expanded. The most well-known concepts are e-learning, online learning, distance learning, the difference of which is discussed, for example, in article (Moore et al., 2011). Let's remind you of main thing in these differences. The term "distance learning” is older. It does not highlight any of communication channels. "Distance education is the most renowned descriptor used when referencing distance learning. It often describes the effort of providing access to learning for those who are geographically distant” (Moore DicksonDeane, Galyen, 2011, P. 129). This term is therefore commonly used as an umbrella term. However, e-learning and online learning emphasize channel specificity: electronic and online. (Moore et al., 2011, pp. 130-131).

In general, it is now recognized that e-learning can be realized in three main form: enhanced, online. "The real test of blended learning is the effective integration of the two main components (face-to-face and Internet technology) such that we are not just adding on to the existing dominant approach or method. This holds true whether it be a face-to-face or a fully Internet-based learning experience. A blended learning design represents a significant departure from either of these approaches. It represents a fundamental reconceptualization and reorganization of the teaching and learning dynamic, starting with various specific contextual needs and contingencies (e.g., discipline, developmental level, and resources). In this respect, no two blended learning designs are identical. This introduces the great complexity of blended learning” 
(Garrison, Kanuka, 2004, P. 97). Thus, as the target audience and technical possibilities expand, the eenvironment studies more often and naturally obtain the form of "blended".

Interactivity with its highly visual component from the very beginning was proclaimed one of the greatest benefits of distance learning. Successful distance education systems involve interactivity between teacher and students, between students and the learning environment, and among students themselves, as well as active learning in the classroom" (Sherry, 1995, P. 344). But today, we are also talking about the drawbacks of this interactivity, the fact that we are returning to the routinized, one-way learning process problem, which is not surprising: any form, even the very alluring and attractive one, can be routinized by only one factor: time. The same routine process is also happening with usual ways of digital communication: reading electronic books, sending text messages, making video calls and videoconferencing, reading Wikipedia, communicating on social networks are common, everyday activities where we do not see anything new or unusual for some time now.

Naturally, studies of distance learning appear, which reveal that the forms of contact are more preferred than distant forms, that they have been given advantage from students. For example, a 2002 study shows that "the data summarized in this report conclude that students show little preference for a live classroom to distance education. To the degree that student satisfaction plays a major role in the assessment or evaluation of instructional effectiveness, distance learning represents a format that students evaluate comparably to other potential formats for a course. The objections to distance education should not be based on the issues related to student satisfaction; students find distance learning as satisfaction as traditional classroom learning formats" (Allen at el., 2002, P. 93).

Today, distance learning is a challenge for professional pedagogical work rather than a universal solution to all problems. It is a challenge that we meet every day, and then we look for ways to realize it in each day's new circumstances, new people, new facts and achievements. I can agree to Thomas M. Duffy and James R. Kirkley words: "These contrasting perspectives characterize the polarized discussions that have arisen around distance education. On the one hand, it is viewed as the next revolution in education, extending the reach of education to those who cannot come to campus, making education more affordable, providing new models for lifelong learning (e.g., through communities of practice), and reforming teaching practices through the emphasis on student discussion and activity, and the elimination of the lecture as the central teaching activity. On the other hand, distance education is seen as lowering the quality of instruction, a moneymaking rather than educational enterprise, an environment where cheating cannot be controlled, and an environment that threatens the teaching role both through the lack of any physical constraints on class size and through the objectification of the "course," thus threatening course ownership and potentially leading to the disaggregation of the roles of faculty” (Duffy, Kirkley, 2004, P. 4).

\section{Methodology and Data analysis}

Turning to the issues of distance learning form, it must be acknowledged that it is related to the search for issues and solutions of the same range. "As institutions of higher education implement programs of distance education, they are faced with the need to implement training programs for existing staff, including administrative, instructional, and support staff, and they find themselves in the position of creating new positions to manage and support the distance education program” (Williams, 2003, P. 46).

I work in a college, where e-studies are recognized as the best in the Baltic region. I will now turn to the practical aspects of distance learning form in the context of higher education. The Alberta College is one of the first private colleges in the independent history of Latvia, whose mission is to build students' ability to be socially active, responsible, willing for further education, to develop students' understanding of starting their own business, creating new jobs, offering to the market talented and creative professionals in business and culture. Values of Alberta College: Opportunity, Professionalism, Openness, Cooperation, Support, Credibility, Unity, Creativity, Innovation. Therefore, the goals of the College are: to prepare qualified specialists in the labor market; to invite graduates to form their own companies; to ensure sustainable college growth; to be among the top three colleges in Latvia; to introduce and use new, innovative methods in education. Therefore, the competitive advantages of the college are formulated as follows: study programs that are practically oriented and demanded by the labor market; individual attitude towards each student; budget 
spots and social support programs; high quality of study process; professional teaching staff; close cooperation with employers; rational investment of funds: success after 2nd year (E-studijas klātienē). Such values, the stated goal, means constant search for forms, ways and methods of learning, including continuous improvement, refinement and new solutions of the digital form. Looking at digital education opportunities and risks, effective seems to be 1) student questionnaire analysis (5-year school year students' 200 questionnaire selection (age ranges from 18 to 36 years, 67\% female, 33\% male) per subject - Rhetoric and presentation skills); and 2) introspection and observation, because it is the daily experience and self-reflection of the tutor, that gives us the information we cannot get by another method. Introspection is one of the oldest research methods, which should not be underestimated because it is based on the acquisition of empirical data by observing their own - usually psychic processes - without the help of any tools and benchmarks.

The time, we enjoy in digital opportunity studies, already shown a number of stereotypes about estudies, among which, the college highlights the following: e-studies resembled boring self-learning process with static study materials and monotonous video recordings due to lack of usual lecture form, where the lecturer meets with the group, help them with study materials; there was a lack of lectures where you can meet fellow students, exchange views and work in groups. To overcome such stereotypes, Alberta College offers its concept of distant education. The college has set up a virtual audience with real-time lectures. Lecturer communicates with students in both individual work with the lecturer, as well as the work in groups. E-study process includes all benefits of full time studies and all opportunities, offered by information technology. In addition to virtual audiences, Moodle system is also used. It holds a wide range of materials for each study subject - summaries, tests, homework and thematic forums for students and teachers.

Thus, Alberta College's e-learning today includes tools that also address the following stereotypes: Alberta College's website as a planner and database, with instructions, requirements, and links needed; Moodle system as a personal interactive library and student meeting place, where you can find lecture summaries, home assignments in all subjects; lecture records, which are especially needed for students who could not participate in the lecture in real time, there are also forums; surveys, ratings; and BigBlueButton (software web conferencing system for GNU/Linux servers) virtual audience, which is also used for guest lectures, administration announcements, study program tutorials, here are also some exams intended. It is important to note that students of distance learning form are also offered the opportunity to attend college - attend classes, conferences, consultations, including exams in college premises. And it has to be admitted that this opportunity has been used regularly: $30 \%$ of students who learn rhetoric and presentation skills in the e-environment choose to take an examination at college premises.

Among other courses, that can be relatively easily adapted to the e-environment, e.g., communication theory, corporate culture, business communication and professional ethics, there are rhetoric and presentation skills. And the subject has raised in me many thoughts on the digital educational opportunities, boundaries and new approaches which are suggested.

\section{Discussion}

Moving the part of the subject that is related to the presentation skills to the e-environment does not cause a big problem: whether it is a material about different programs in creating presentations, or inserting text and images into a slide, or effective combinations of colors, shapes, etc. This material is grateful, and the feedback in communication with the students confirms this: students admit that and how they try for the first time Canva.com, they send screenshots with their works in these programs, they tell for what purposes they will use Prezi.com in their future activities, what they understood, recommend to others, how they will act in their professional life.

Meanwhile, transfer of rhetoric involves a number of issues: in distance it is more difficult to construct a lesson on techniques of attracting attention, as there is no room with listeners in different areas. There is also the question of how the student can demonstrate the potential of movement and pace in real situations; also about worry and stress reduction techniques - how to train breathing techniques, how to control breathing; and one of the biggest challenges is the use of arguments and sophism in discussion. 
One of the solutions - e-studies in presence - is included in our college study form. Students have the opportunity to come to college. The wish of using this option is written by the students in questionnaires every year. Considering the small territory of Latvia and the possibilities of public transport, they can visit Riga a few times a year, combining the trip, for example, with a meeting with scientific supervisor of his/her qualification work, or attending Latvian opera or a theater, or visit Latvian National Library, or participating in audience work or individual consultation. Students working abroad, for example, in the UK, Ireland, Spain, have a tradition of visiting their homeland around Christmas, and students tend to combine this visit with a college visit during the session. At such meetings or examinations or counseling becomes a synthetic learning activity: students both present their presentations and acquire technical breathing, using different methods of attention. Within five years I have developed the following options for planning: here, it is important to 1) schedule appointments closer to the holidays, 2) preferably shortly before the official exam date, make an appointment in both the Moodle system and on-site auditorium, 3) not later than one and a half months before the on-site consultation place these dates and times for students in Moodle's informational section, including the forum.

In case such visits are not possible for the student, it is necessary to use the wide digital possibilities, as during COVID-19. In this case, the most important thing is - nothing new - the purpose of the e-learning. The practical purpose of rhetoric is to develop skills in public speaking. A special visual material, for example, - short fragments, showing the professions concerned, are selected; material analysis takes place in the forum and also in homework. The shortness of the material is principled, because long fragments could contribute to the negative perception of one-way communication. It is important in selecting such material to avoid populist materials, such as politicians failing, discussing or clumsiness. Such material, as experience has shown, must be marginal so that it does not give the students an incorrect idea of the specifics of public speech: it is not just a matter of politicians. Therefore, each group is provided with material showing a representative of their profession: becoming tourism professionals are provided with video materials showing tourism operators, tour guides and specialists in the field of culture, becoming marketing specialists analyze speeches of professionals in their field, etc.

Another principle in distance form of rhetoric: students are offered tasks in which they have to select fragments that show both communicative successes and failures in order to not only seek negative, wrong details, but to stimulate dialogue and reviews with themselves. Modern public space could be perceived as tendentious, as it is more common to post failure, ridiculous curiosity of public figures (e.g. social networking effect). Therefore, the principle of symmetry is used in students' tasks, which, as experience shows, is effective and efficient, as evidenced by students' annual surveys.

Another element of the subject that shows positive effects is the presentation drafts in various presentation programs with a developed speech plan: such students try different possibilities, look for themselves in them, write about what suits them and what doesn't. This is one of the most important tasks in which students have the opportunity not only to find out different presentation programs (with intimately clear software), but also to explore their image, to find out how and to what extent a student fits or does not, suits or does not to a particular presentation type. Students in their homework responses and surveys show that they have realized that, for example, they will use Canva.com opportunities for presenting events and successes of their company.

During COVID-19, it was important not to lose the regularity of classes or to change the requirements and scope of tasks. At the beginning of COVID-19, this seemed a challenge, but over time it proved realistic, including the organization of guest lectures: professionals from various fields showed solidarity and hospitality by accepting invitations to conduct a guest lecture in the e-environment.

\section{Conclusion}

Today's digital education opportunities have become widely used, therefore, teachers' work is threatened by becoming routinized, and for students - a passive perception of learning material. If digital education opportunities are not realized blended and in the form of one-way communication (informing), but in two-way communication, taking care of the diversification of techniques, combining the benefits of digital and real space, the methodological success could be achieved during COVID-19. Ultimately - using two-way 
communication, digital and real-space capabilities and symmetry principles in material selection, and ensuring the feedback - in the subject of rhetoric and presentation skills, students not only learn the course but also understand themselves, their bodies, specifics of their communication skills, as well as the differences, risks and benefits of real or digital communication.

Cite this article as: Milevica I. (2020) Rhetorics and challenges of distant education. Materials of International Practical Internet Conference "Challenges of Science”. Issue III, 2020. Pp.: 131-136. https://doi.org/10.31643/2020.018

\section{Refrences}

Allen, Mike, Bourhis, John, Burrell, Nancy, Mabry, Edward. Comparing Student Satisfication With Distance Education to Traditional Classrooms in Higher Education: A Meta-Analysis. The American Journal of Distance Education. 16 (2), 2002, pp. 83-97. DOI: 10.1207/S15389286AJDE1602_3

Arlinwibowo, J., Retnawati, H., Kartowagiran, B., Kassymova, G.K. (2020) Distance learning policy in Indonesia for facing pandemic COVID-19: School reaction and lesson plans. Journal of Theoretical and Applied Information Technology, 98(14), $2828-2838$.

Crawford, Joseph, Butler-Henderson, Kerryn, Rudolph, Jürgen, Malkawi, Bashar, Glowatz, Matt, Burton, Rob, Magni, Paola A., Lam, Sophia (2020) COVID-19: 20 countries' higher education intra-period digital pedagogy responses. Journal of Applied Learning \& Teaching. Vol.3 No.1 (2020), 9-28. DOI: 10.37074/jalt.2020.3.1.7

Dhawan, Shivangi (2020) Online Learning: A Panacea in the Time of COVID-19 Crisis. Journal of Educational Technology Systems, Vol. 49(1) (2020), 5-22. doi: 10.1177/0047239520934018

Duffy, Thomas, M., Kirkley, Jamie R.Theory and Practice in Distance Education. Learner-Centred Theory and Practice in Distance Education: Cases From Higher Education. Lawrence Erlbaum Associates, Publisher Mahwah, New Jersey, London, 2004, 3-15.

E-studijas klātienē. Retrived from https://alberta-koledza.lv/contents.php?parent=373 Latest access: 23.09.2020.

Garrison, D. Randy, Kanuka, Heather. Blended Learning: Uncovering its Transformative Potential in Higher Education. Internet and Higher Education, 7 (2004), 95-105. DOI: 10.1016/j.iheduc.2004.02.001

Hebebci, M. T., Bertiz, Y., \& Alan, S. (2020). Investigation of views of students and teachers on distance education practices during the Coronavirus (COVID-19) Pandemic. International Journal of Technology in Education and Science (IJTES), 4(4), $267-282$. DOI: https://doi.org/10.46328/ijtes.v4i4.113

Moore, Joi L., Dickson-Deane, Camille, Galyen, Krista. E-Learning, online Learning, and Distance Learning environments: Are they the same? Internet and Higher Education. 14 (2011), 129-135. DOI: 10.1016/j.iheduc.2010.10.001

Sherry, Lorraine. Issues in Distance Learning. International Jl. of Educational Telecommunications (1995), 1(4), 337-365.

Williams, Peter, E. Roles and Competencies for Distance Education Programs in Higher Education Institutions. The American Journal of Distance Education, 2003, 17(1), 45-57. DOI: 10.1207/S15389286AJDE1701_4 